\title{
How Does Frontline Employees' Perceived External Reputation Affect Service Innovation Implementation? A Dual-Path Model
}

\author{
Mario Schaarschmidt and Gianfranco Walsh
}

\begin{abstract}
Service firms typically focus on increasing their operational proficiency and generating service innovations to stay competitive (Wilder et al. 2014). Researchers as well as practitioners widely acknowledge that service innovation especially is crucial for service organizations' financial performance (e.g., Ordanini and Parasuraman 2011). However, in contrast to research that centers on firm-level data, research that is devoted to employees' roles in generating and delivering service innovations remains rare (Cadwallader et al. 2010). Customer contact personnel especially are important to execute service offerings. Or, as Zeithaml et al. (2009, p. 352) state, "employees are the service" in many people-processing services. Frontline service employees are also important to successfully introduce and explain services to customers. Thus, through their motivation to recommend newly designed service offerings to customers (or not), service employees are in a position to either promote or impede service innovation implementation (McKnight and Hawkrigg 2005).

The authors draw on two theoretical perspectives in the innovation literature, that is, the efficiency-oriented perspective and the social-political perspective, in conjunction with social identity theory to predict how employees' perceived external reputation affect service innovation implementation. We test resulting hypotheses with two data sets from German $(N=150)$ and the USA $(N=208)$-based frontline service employees. Results imply that the path from perceived external reputation to employees' willingness to recommend service innovations is significant across both studies. In addition, the path is fully mediated by expected positive performance outcomes and expected reputational gains. The authors discuss implications for practice and for innovation and marketing theory.
\end{abstract}

References available upon request.

\author{
M. Schaarschmidt $(\triangle)$ \\ University of Koblenz-Landau, Mainz, Germany \\ e-mail: mario.schaarschmidt@uni-koblenz.de \\ G. Walsh \\ Friedrich-Schiller-University of Jena, Jena, Germany \\ e-mail:walsh@uni-jena.de
}

L. Petruzzellis, R.S. Winer (eds.), Rediscovering the Essentiality of Marketing, Developments in Marketing Science: Proceedings of the Academy of Marketing Science, DOI 10.1007/978-3-319-29877-1_161 